\title{
Factors affecting nest-site selection of Sabine's Gulls in the eastern Canadian Arctic
}

\author{
Iain J. Stenhouse, H. Grant Gilchrist, and William A. Montevecchi
}

\begin{abstract}
The selection of breeding habitat is of prime importance for individual fitness. Among birds, natural selection should favour the ability to recognize and select habitat suitable for nesting and rearing chicks. This study compares the characteristics of Sabine's Gull, Xema sabini (Sabine, 1819), nest sites with random points across a coastal tundra environment on Southampton Island, Nunavut, Canada. The availability of terrestrial invertebrate prey was also examined among habitats. Sabine's Gull nests were nonrandomly distributed in relation to vegetation, substrate, and proximity to water. Gulls nested within approximately $1 \mathrm{~km}$ of the coastline and selected sites with the greatest proportions of moss and standing water (i.e., they nested close to the edge of small freshwater ponds near shore). However, there were no detectable differences in characteristics between successful and unsuccessful nests within preferred habitat. The dynamics of terrestrial invertebrate prey communities varied between years, but the volume of invertebrates in Sabine's Gull nesting habitat was intermediate between the most productive habitats and the least productive habitats in both years. However, nest-site selection in Sabine's Gulls may also be influenced by the availability of aquatic invertebrates (not examined in this study) and their proximity to the marine coastline, where chicks are taken to be reared.

Résumé : La sélection de l'habitat de reproduction est d'importance primordiale pour la fitness individuelle. Chez les oiseaux, la sélection naturelle devrait favoriser la capacité à reconnaître et à choisir un habitat adéquat pour la nidification et l'élevage des poussins. Notre étude compare les caractéristiques des sites de nidification de la mouette de Sabine, Xema sabini (Sabine, 1819), à celles de points aléatoires au travers d'une toundra côtière sur l'île de Southampton, Nunavut, Canada. Nous avons aussi mesuré la disponibilité des proies invertébrés dans les différents habitats. Les nids des mouettes de Sabine sont répartis de façon non aléatoire en fonction de la végétation, du substrat et de la proximité de l'eau. Les mouettes nichent à moins d'environ un kilomètre de la côte et choisissent les sites qui contiennent la plus forte proportion de mousses et d'eau stagnante (c'est-à-dire qu'elles nichent en bordure de petits étangs d'eau douce près de la côte). Cependant au sein de cet habitat préféré, il n'y a pas de différences décelables entre les caractéristiques des nids qui ont connu ou non un succès. La dynamique des communautés de proies invertébrées terrestres varie d'une année à l'autre, mais le volume des invertébrés dans l'habitat de nidification des mouettes de Sabine est intermédiaire entre ceux des habitats les plus et les moins productifs durant les deux années. Toutefois, la sélection des sites de nidification chez la mouette de Sabine peut aussi être influencée par la disponibilité des invertébrés aquatiques, ce qui n'a pas été examiné ici, ainsi que par la proximité de la côte marine où les poussins sont amenés durant l'élevage.
\end{abstract}

[Traduit par la Rédaction]

\section{Introduction}

It is generally expected that the majority of individuals of a species will select breeding habitat that provides optimal conditions for survival and reproduction (Cody 1985). Thus, birds should select features of their environment that maximize their chances of successfully rearing chicks. The greatest influences on breeding-habitat selection are considered to be safety from predators and access to food (Lack 1968). These factors are not mutually exclusive, however, and some trade-off between the two may exist when birds are selecting specific nest sites (Martin 1992, 1995).
In a flat landscape with short vegetation and limited habitat structure, factors influencing nest-site selection may be subtle. Habitat features such as substrate, hydrology, topography, vegetation, local climate, and the presence or absence of conspecifics and (or) other species may have considerable influence on nest-site selection and reproductive success (Cody 1985). Furthermore, the proximity and availability of prey in relation to specific habitat characteristics may play a major role in nest-site selection (Buckley and Buckley 1980).

Across the Arctic, the Sabine's Gull, Xema sabini (Sabine, 1819), nests in low-lying, coastal wetland tundra (Day et al. 2001). It is considered an unusual gull, recognized as phylo-

Received 4 February 2004. Accepted 26 July 2005. Published on the NRC Research Press Web site at http://cjz.nrc.ca on 22 September 2005.

I.J. Stenhouse $\mathrm{e}^{1,2}$ and W.A. Montevecchi. Cognitive and Behavioural Ecology Programme, Memorial University of Newfoundland, St. John's, NL A1B 3X9, Canada.

H.G. Gilchrist. Canadian Wildlife Service, National Wildlife Research Centre, Carleton University, Ottawa, ON K1A 0H3, Canada.

${ }^{1}$ Corresponding author (e-mail: istenhouse@ audubon.org).

${ }^{2}$ Present address: Audubon Alaska, 715 L Street, Suite 200, Anchorage, AK 99501, USA. 
Table 1. Characteristics of the six habitat types in the study area at East Bay, Southampton Island, Nunavut, from marine shoreline inland (after Smith 2003).

\begin{tabular}{|c|c|}
\hline Habitat & Characteristics \\
\hline Intertidal zone & $\begin{array}{l}\text { Exposed silt and rock; within splash range of fall storms and influenced by salt spray; sparse and patchy } \\
\text { moss and grass or sedge }\end{array}$ \\
\hline Moss carpet & $\begin{array}{l}\text { Moss covers substrate; sparse to moderate grass or sedge; patchy and sparse herbs; typical of pond edges } \\
\text { between coastal and inland habitats }(0-1 \mathrm{~km})\end{array}$ \\
\hline Sedge meadow & $\begin{array}{l}\text { Moss covers substrate; grass and sedge tall and dense; herbs abundant and diverse; few rocks; flat to } \\
\text { hummocked; typical of moist areas far }(1-2 \mathrm{~km}) \text { from shore }\end{array}$ \\
\hline Dry heath & $\begin{array}{l}\text { Ericaceous shrubs dominant; some willows and lichens abundant; herbs moderate in richness and abundance; } \\
\text { substrate a mix of soil, rock, and gravel; flat to hummocked; typical in drier areas farther from shore }\end{array}$ \\
\hline Gravel ridge & $\begin{array}{l}\text { Bare gravel with sparse vegetation at low edges; small patches of herbs and lichens in highest and driest } \\
\text { areas; visibly raised (up to } 5 \mathrm{~m} \text { ) from the surrounding area }\end{array}$ \\
\hline
\end{tabular}

genetically distinct (Chu 1998) and atypical in several aspects of its behaviour (e.g., its distraction display; Brown et al. 1967) and reproductive biology (e.g., short incubation and fledging periods; Stenhouse et al. 2001). However, this species does display some typical gull breeding behaviour: both sexes exhibit high reproductive investment and share parental activities such as incubation and aggression towards potential predators (Stenhouse et al. 2004). In the eastern Canadian Arctic, where salt water remains ice-covered for much of the season, Sabine's Gulls feed primarily on terrestrial and freshwater invertebrates during the breeding season (Abraham and Ankney 1984). On the northern tundra, where nest predation is highly variable and extremely intense in some years, Sabine's Gulls rarely leave their nests completely unattended for extended periods (Stenhouse 2003; Stenhouse et al. 2005). Nesting in areas in close proximity to a high abundance of their invertebrate prey could increase reproductive success, as foraging close to their nests likely reduces the time spent away from the nest and, thus, the risk of losing eggs to nest predators, particularly avian predators that can appear and raid nests swiftly. However, nest-site selection may also be influenced by factors other than foraging opportunities (i.e., what makes good nesting habitat may not necessarily provide the optimal foraging environment), and Sabine's Gulls may face a trade-off between nest attendance and efficient foraging.

This study identifies the specific characteristics of Sabine's Gull nest sites at different scales. Specifically, we compare the characteristics of nest sites with $(i)$ random points across a $2 \mathrm{~km} \times 2.5 \mathrm{~km}$ study area and (ii) random points within preferred Sabine's Gull nesting habitat. We also compare characteristics of successful nests with those of unsuccessful nests and examine the general availability of terrestrial invertebrates in relation to habitat.

\section{Methods}

This study was carried out in the East Bay Migratory Bird Sanctuary $\left(64^{\circ} 01^{\prime} \mathrm{N}, 81^{\circ} 47^{\prime} \mathrm{W}\right)$, Southampton Island, Nunavut, in the eastern Canadian Arctic, from May to August 19982001. The Sanctuary encompasses an area of approximately $1200 \mathrm{~km}^{2}$ and, despite being located within the Low Arctic region, is generally High Arctic in character, influenced in its ecological and physical characteristics by the deep, cold waters of the Foxe Channel. Landfast sea ice can remain in East Bay well into July, and daily minimum temperatures often remain close to freezing throughout summer.

The study area is a $2 \mathrm{~km} \times 2.5 \mathrm{~km}$ block of low-lying, coastal wetland tundra on the southern shore of East Bay with a complex of brackish and freshwater ponds typical of the area. Within the plot, habitats are few and distinct and can be categorized into six general types. These are, from the coastline inland, intertidal zone, moss carpet, sedge meadow, scrub willow, dry heath, and gravel ridge (Table 1). These habitat types generally run in broad bands parallel to the shoreline and become drier with increasing distance from the coast.

In general, the intertidal zone is colonized by few plants and is characterized by bare sandy or rocky substrate. Wetland areas are characterized by moss (Campylium stellatum (Hedw.) C. Jens. and Scorpidium scorpioides (Hedw.) Limpr.), sedge (Carex aquatilis Wahlenb. and C. subspathacaea Wormsk. ex Hornem.), and grass (Arctagrostis latifolia (R. Br.) Griseb.). Drier inland areas are dominated by dwarf shrubs, particularly willows (Salix L. spp.) and mountain-avens (Dryas integrifolia Vahl), broken by raised, bare gravel ridges generally running parallel to shore. As a product of the low relief, brackish ponds extend several hundred metres from the marine shoreline.

\section{Nest sites}

Within the study area, Sabine's Gull nests were located by searching on foot. The location (latitude and longitude \pm 0.1 seconds) of each nest was recorded with a handheld global positioning system unit (Garmin GPS II Plus, Garmin International Inc., Olathe, Kansas), and nests were marked on aerial photographs. Coordinates were entered into MapInfo ${ }^{\circledR}$ (MapInfo Pro, version 5.0, MapInfo Corp., Troy, New York) as decimal degrees. Mean inter-nest distances were calculated in MapInfo using a MapBasic ${ }^{\circledR}$ programme called CalcDist. Nests were visited approximately every 3 days throughout incubation and hatching (except during extreme weather) to identify losses to predation.

At each nest, details of the location, vegetation, substrate, and distance to water were recorded. Within a $1-\mathrm{m}^{2}$ quadrat centred on each nest, the percentage of ground cover was estimated by eye for each of the following vegetation or sub- 
strate types: sedge, heath (ericaceous shrubs), moss, exposed soil, rock or gravel, and standing water.

\section{Vegetation characteristics}

To characterize vegetation types within the study area, a representative plot of $1.5 \mathrm{~km} \times 1.5 \mathrm{~km}$ was divided into 16 transects running perpendicular to the shore. Vegetation sampling locations were spaced at 50-m intervals along each transect. A random sample of 80 points was also drawn from across the entire study area (from points that fell on transects $0,4,8$, and 12). Twenty-two of these points fell on open water and were discarded, leaving a sample of 58 locations from across the study area. A further 30 random points that fell in moss carpet (preferred nesting habitat, see below) were used to represent Sabine's Gull nesting habitat. Within a $1-\mathrm{m}^{2}$ quadrat at each location, the percentage of ground cover was estimated in the same manner and using the same categories as noted above for nests, as was the distance to the nearest water body.

\section{Prey availability}

The relative temporal and spatial availability of terrestrial invertebrates in each habitat type was quantified in 2000 and 2001 using pitfall traps. These consisted of round plastic containers, $108 \mathrm{~mm}$ in diameter, with a circumference of $340 \mathrm{~mm}$. They were placed flush with the substrate and filled with approximately $1 \mathrm{~cm}$ of propylene glycol. Trap contents were filtered through a reusable coffee filter, all invertebrates were collected, and the filter was flushed clean between each sample collection. Rarely, a few traps were lost owing to the combination of rising groundwater and strong winds.

Sampling was stratified by habitat, with 20 pitfall traps set at random points within nonrandomly chosen patches of six broad habitat categories (Table 1). Each trap was placed at least 3-4 $\mathrm{m}$ from the next, and all traps were placed well within a patch (i.e., avoiding edge effects). In 2000, all traps were placed in habitat patches in the western half of the study area. They were set out on 30 June, and the contents were collected on three occasions over the breeding season (8, 16, and 24 July). In 2001, traps were divided evenly between the sites sampled in 2000 and similar sites in the eastern half of the study area. Traps were set out on 21 June and emptied on four occasions (29 June and 7, 15, and 23 July). Invertebrates were stored in $70 \%$ alcohol and later classified to species, where possible, or genus.

An index of the biomass of invertebrates in each habitat was estimated by measuring the mean volume per individual for each invertebrate species or genus and then multiplying this by the number of individuals present in each sample (Vollenweider 1969). The mean volume of each invertebrate was calculated as follows: individuals from each species or genus were placed in a known quantity of fluid in a graduated cylinder until a measurable amount (at least $0.2 \mathrm{~mL}$ ) was displaced; this was repeated five times, and an overall mean was established.

Although the use of pitfall traps in ecological studies has a long history, these traps are known to be selective for different invertebrate species and different life stages (Topping and Sunderland 1992). That is, the mobility of a specific invertebrate species, or life stage, influences the probability
Table 2. Mean $( \pm \mathrm{SE})$ percentage ground cover of vegetation types $\left(1-\mathrm{m}^{2}\right.$ quadrats) and distance to nearest water at random points across the study area $(n=58)$, random points within nesting habitat $(n=30)$, and Sabine's Gull (Xema sabini) nests $(n=$ 70) at East Bay, Southampton Island, Nunavut.

\begin{tabular}{lrrr}
\hline & \multicolumn{1}{l}{$\begin{array}{l}\text { Study } \\
\text { area }\end{array}$} & \multicolumn{1}{l}{$\begin{array}{l}\text { Nesting } \\
\text { habitat }\end{array}$} & \multicolumn{1}{c}{ Nests } \\
\hline \% cover & $5 \pm 0.79$ & $8 \pm 1.37$ & $4 \pm 2.16$ \\
Sedge & $24 \pm 3.93$ & 0 & 0 \\
Heath & $3 \pm 0.66$ & $3 \pm 1.10$ & $3 \pm 1.20$ \\
Willow & $38 \pm 5.28$ & $71 \pm 4.70$ & $80 \pm 2.94$ \\
Moss & $10 \pm 2.82$ & $14 \pm 2.86$ & $<1 \pm 0.26$ \\
Exposed soil & $20 \pm 3.53$ & $7 \pm 2.36$ & $2 \pm 0.45$ \\
Rock or gravel & $<1 \pm 0.03$ & $<1 \pm 0.17$ & $10 \pm 1.71$ \\
$\quad$ Standing water & $25.0 \pm 3.43$ & $10.9 \pm 2.58$ & $0.7 \pm 0.08$ \\
Distance to water (m) & & & \\
\hline
\end{tabular}

that it will fall into a trap. However, pitfall traps are useful for measuring the abundance of invertebrates active on the substrate (Van den Berghe 1992). Although the details of the diet of Sabine's Gulls at East Bay (such as preferred species or genera) remain unknown, these birds clearly react to and catch invertebrates moving on the ground while foraging (personal observations).

\section{Statistical analyses}

A principal components analysis was used to reduce the number of variables in the habitat data. Two-tailed $t$ tests were used to compare principal component scores between groups, such as nests and random points, and to compare the proximity of nests and random points to the nearest water. Analysis of variance was used to compare the biomass of invertebrates among habitats and between years, and a $\chi^{2}$ test was used to compare the number of nests on islands versus pond edges among years. Analyses were carried out using DataDesk statistical software version 6.1 (Data Description Inc., Ithaca, New York). Throughout, statistical significance was recognized at $P \leq 0.05$, and values reported are means \pm SE.

\section{Results}

\section{Vegetation characteristics of study area}

On average, $1-\mathrm{m}^{2}$ quadrats at random points across the study area consisted of moss $(38 \%)$, heath $(24 \%)$, and rock or gravel $(20 \%)$, with small amounts of sedge $(5 \%)$ and willow $(3 \%)$ and very little standing water $(0.03 \%$; Table 2$)$.

In the principal components analysis, the first principal component (PC1) explained $31 \%$ of the variance, while the second component explained only $17 \%$ (Table 3 ). Moss, a damp habitat, loaded negatively for PC1. Heath, rock or gravel, and exposed soil, which are drier habitat types, all loaded positively for PC1, suggesting that this component is a general measure of moisture content.

\section{Vegetation characteristics of nesting habitat}

Vegetative cover within the band of preferred nesting habitat was much less varied than that over the entire study area (Table 2). On average, $1-\mathrm{m}^{2}$ quadrats at random points 
Fig. 1. Distribution of Sabine's Gull (Xema sabini) nests in the study area at East Bay, Southampton Island, Nunavut, in each year.

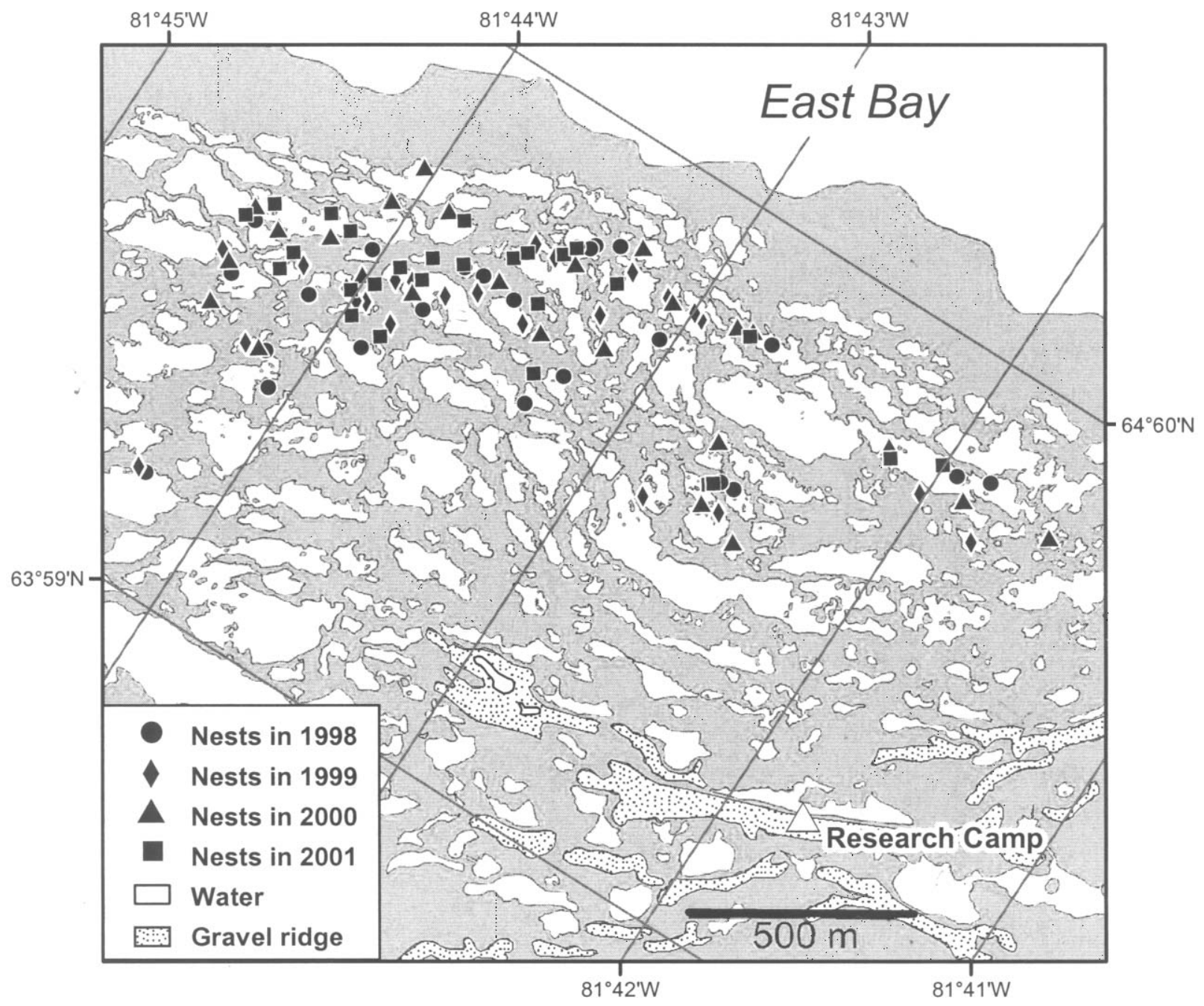

Table 3. Habitat variables, component loadings, and eigenvalues for the first three principal components (PCs) of $1-\mathrm{m}^{2}$ quadrats centred on Sabine's Gull nests, random points across the study area, and random points within nesting habitat at East Bay, Southampton Island, Nunavut.

\begin{tabular}{lccc}
\hline & PC1 & PC2 & PC3 \\
\hline Variable & & & \\
Sedge & 0.24 & 0.66 & 0.27 \\
Heath & 0.63 & -0.50 & 0.19 \\
Willow & 0.19 & -0.07 & 0.70 \\
Moss & -0.95 & 0.03 & 0.11 \\
Exposed soil & 0.43 & 0.62 & -0.38 \\
Rock or gravel & 0.71 & -0.22 & -0.29 \\
$\quad$ Standing water & -0.32 & -0.27 & -0.49 \\
Eigenvalue & 2.19 & 1.20 & 1.09 \\
\% variation explained & 31.2 & 17.1 & 15.3 \\
Total \% variation explained & 31.2 & 48.3 & 63.8 \\
\hline
\end{tabular}

within the nesting habitat were dominated by moss (71\%), with a considerable amount of exposed soil (14\%) and more standing water $(0.17 \%)$. There were no ericaceous shrubs (heath) recorded in this habitat (Table 2).

\section{Nesting distribution}

In all years, Sabine's Gull nests at East Bay occurred only in moss carpet habitat, in a band approximately 200 to $1100 \mathrm{~m}$ from shore (Fig. 1). The proportion of Sabine's Gull nests located on small islands within ponds (versus pond edges) ranged from $22 \%-40 \%$ and was not significantly different among years $\left(\chi_{3}^{2}=2.41, P=0.49\right)$. Due to runoff and evaporation, the area of ponds often changed over the course of the breeding season at East Bay, so that nests originally on small islands occurred on pond edges by mid to late July.

The amounts of sedge and willow at Sabine's Gull nest sites were similar to those at random points across the entire study area, but nests were strikingly different from random points in all other vegetation types and in their proximity to standing water (Table 2). There was a highly significant difference between the mean PC1 scores for nests $(-0.61 \pm$ $0.06, n=70)$ and those for random points across the study area $\left(0.78 \pm 0.14, n=58 ; t_{77}=-9.1, P \leq 0.0001\right)$, indicating that Sabine's Gulls nested in damp, mossy areas. There was also a highly significant difference in the mean distance to nearest water between nests $(0.67 \pm 0.08 \mathrm{~m}, n=65)$ and random points across the study area $(25.0 \pm 3.43 \mathrm{~m}, n=57$; $\left.t_{56}=-7.10, P \leq 0.0001\right)$, indicating that Sabine's Gulls typically nested within a few metres of pond edges. 
Within the preferred Sabine's Gull nesting habitat (i.e., moss carpet), the amount of willow around nests was similar to the amount at random points. However, even within this habitat, nests were again strikingly different from random points in the proportions of all other vegetation types (Table 2). The proportions of moss cover and standing water were much higher at nests because the gulls nested at the edges of ponds. There was a highly significant difference between PC1 scores for nests $(-0.61 \pm 0.06, n=70)$ and those for random points within the nesting habitat $(-0.08 \pm 0.12$, $\left.n=30 ; t_{44}=-4.0, P \leq 0.0001\right)$, indicating that, even at this finer scale, nests were nonrandomly distributed and Sabine's Gulls nested in particularly mossy sites. There was also a highly significant difference in the mean distance to nearest water between nests $(0.67 \pm 0.08 \mathrm{~m}, n=65)$ and random points within the preferred nesting habitat $(10.93 \pm 2.58 \mathrm{~m}$, $\left.n=30 ; t_{29}=-3.97, P=0.0004\right)$, with nests being much closer to water.

\section{Successful and unsuccessful nests}

Nest success is highly variable among years in Sabine's Gulls at East Bay (Stenhouse et al. 2001). Over the years of this study, egg predation accounted for $87 \%-100 \%$ of nest failures. Flooding early in the season can also have an effect in some years but was a relatively minor cause of nest failure throughout this study, accounting for $0 \%-8 \%$ of nest failures.

There were no differences in the mean PC1 scores between successful $(-0.67 \pm 0.06, n=41)$ and unsuccessful nests $\left(0.54 \pm 0.11, n=29 ; t_{68}=-1.07, P=0.29\right)$ or in the mean distance to nearest water between successful $(0.56 \pm$ $0.07 \mathrm{~m}, n=38)$ and unsuccessful nests $(0.83 \pm 0.16 \mathrm{~m}, n=$ $\left.27 ; t_{36}=-1.50, P=0.14\right)$. However, the variance around the mean PC1 scores for unsuccessful nests was twice that of successful nests.

\section{Prey availability}

During incubation, Sabine's Gulls were observed to forage on terrestrial invertebrates close to their nests $(<100 \mathrm{~m})$ and further afield within the nesting habitat (personal observations). The biomass of terrestrial invertebrates across the study area differed among habitats $\left(F_{[5,41]}=7.77, P=0.003\right)$ and throughout the season $\left(F_{[3,41]}=15.0, P=0.0005\right)$, but not between years $\left(F_{[1,41]}=2.46, P=0.15\right)$. There were no significant interactions. Generally, dry heath, scrub willow, and sedge meadow harbored a consistently greater volume of invertebrates throughout the breeding season, compared with bare gravel and the intertidal zone (Fig. 2). However, the volume of invertebrates in the moss carpet habitat, where Sabine' Gulls nested, was mostly intermediate between these groups (Fig. 2).

\section{Discussion}

With respect to habitat, Sabine's Gull nests were nonrandomly distributed throughout the study area, as birds nested only in damp, mossy areas. Nests were also nonrandomly distributed within the preferred nesting habitat, where Sabine's Gulls nested in particularly mossy sites close to standing water (i.e., at pond edges). Interestingly, there were no significant differences detected between successful
Fig 2. Total volume $(\mathrm{mL})$ of terrestrial invertebrates in each habitat type at East Bay, Southampton Island, Nunavut, in 2000 and 2001.

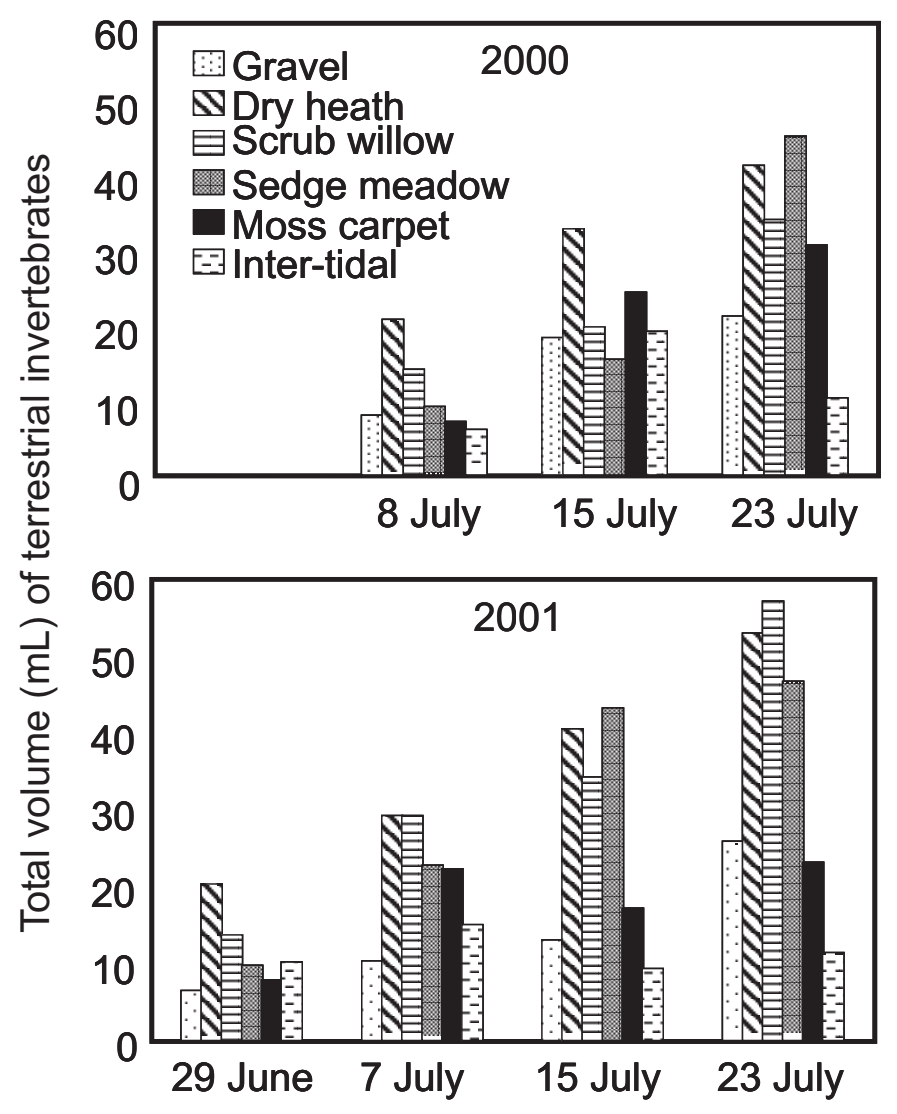

and unsuccessful nests within the nesting habitat. Although natural selection is expected to occur when there are differences between successful and unsuccessful nests, differences of this type are likely to be subtle and difficult to detect, given available sample sizes (Martin 1988). However, the considerably greater variance around the mean PC1 scores for unsuccessful nests suggests that there may be higher nest failure at the extremes of the habitat gradient. Thus, breeding-habitat selection in Sabine's Gulls may be under the influence of stabilizing natural selection (Clark and Shutler 1999). That is, the choice of specific characteristics found at successful nests is constantly reinforced through the process of natural selection.

Over the course of the breeding season, shallow ponds at East Bay can dry up completely, especially in inland areas and close to shore (personal observations). In the moss carpet habitat, however, ponds often shrink but rarely dry up completely. Therefore, the preferred nesting habitat may also be the least variable from year to year in terms of the amount of water retained in ponds over the summer. Sabine's Gulls also feed in ponds within their nesting habitat during incubation, particularly freshwater ponds (Abraham and Ankney 1984), and their breeding-habitat selection may also be influenced by differences in the production and availability of aquatic invertebrates among habitats. Quantifying the relative abundance of aquatic invertebrates should be considered in future studies of this species. 
Although Sabine's Gulls at East Bay spend a considerable amount of time feeding in the vicinity of their nests, the moss carpet habitat in which they nest was not the most productive of terrestrial invertebrates. Moss carpet was intermediate between the most productive habitats (dry heath, scrub willow, and sedge meadow, generally $1-2 \mathrm{~km}$ inland) and the least productive habitats (gravel ridge and intertidal zone, both at the margins of the study area). However, moss carpet was the most productive habitat closest to the shore of the bay, where breeding Sabine's Gulls take their chicks immediately after hatch (Forchhammer and Maagaard 1991; Stenhouse et al. 2001). Thus, the preferred nesting habitat may also reflect a trade-off between terrestrial foraging opportunities and proximity to shore during chick rearing.

On the small island of Renskaeret in northeast Greenland, where there are no freshwater ponds, Sabine's Gulls forage in salt water, at openings in sea ice, throughout the breeding period (Forchhammer and Maagaard 1991). In contrast, ice cover is generally solid in East Bay until early July, preventing Sabine's Gulls from foraging in salt water during incubation. However, East Bay is largely free of ice by mid-July, when Sabine's Gull chicks hatch (Stenhouse et al. 2001). Thus, movement to the shore immediately after hatch may reflect the need for adults to feed in salt water while remaining near their chicks. By nesting in moss carpet habitat, Sabine's Gulls $(i)$ nest in the most productive habitat nearest to shore, (ii) limit the distance they have to move their small, flightless chicks after hatch, and (iii) avoid drier inland areas where their predators breed (arctic fox, Alopex lagopus (L., 1758); Herring Gull, Larus argentatus Pontoppidan, 1763; and Jaegers, Stercorarius spp. Brisson, 1760), which may reduce the likelihood of nest predation.

\section{Acknowledgements}

We are grateful to the community of Coral Harbour for permission to work in East Bay, Southampton Island, Nunavut. We are deeply indebted to R. Bryant and P.A. Smith for assistance in the field and to all members of the East Bay field crews over the years of this study, particularly K. Truman and K. Allard. This research was supported by the Northern Conservation Division of the Canadian Wildlife Service (H.G.G.), the Natural Sciences and Engineering Research Council of Canada (via a Discovery Grant to W.A.M.), and Memorial University of Newfoundland (via a Graduate Fellowship and the Hatcher Scholarship to I.J.S.). We sincerely thank G.J. Robertson, R.F. Rockwell, and J.-F. Giroux, whose comments improved an earlier version of the manuscript.

\section{References}

Abraham, D., and Ankney, C.D. 1984. Partitioning of foraging habitat by breeding Sabine's Gulls and Arctic Terns. Wilson Bull. No. 96(2): 161-172.
Brown, R.G.B., Blurton-Jones, N.G., and Hussell, D.J.T. 1967. The breeding behaviour of Sabine's Gull (Xema sabini). Behaviour, 28: $110-140$.

Buckley, F.G., and Buckley, P.A. 1980. Habitat selection in marine birds. In Behavior of marine animals. Vol. 4. Edited by J. Burger, B.L. Olla, and H.E. Winn. Plenum Press, New York. pp. 69-112.

Chu, P.C. 1998. A phylogeny of the Gulls (Aves: Larinae) inferred from osteological and integumentary characteristics. Cladistics, 14(1): 1-43.

Clark, R.G., and Shutler, D. 1999. Avian habitat selection: pattern from process in nest-site use by ducks? Ecology, 80(1): 272287.

Cody, M.L. 1985. Habitat selection in birds. Academic Press, Orlando, Fla.

Day, R.H., Stenhouse, I.J., and Gilchrist, H.G. 2001. Sabine's Gull (Xema sabini). In The birds of North America. No. 593. Edited by A. Poole and F. Gill. The Birds of North America, Inc., Philadelphia, $\mathrm{Pa}$.

Forchhammer, M., and Maagaard, L. 1991. Breeding biology of Sabine's Gull (Larus sabini) in Northeast Greenland. Dan. Ornitol. Foren. Tidsskr. 85: 53-62.

Lack, D. 1968. Ecological adaptations for breeding in birds. Methuen, London.

Martin, T.E. 1988. Processes organizing open-nesting bird assemblages: competition or nest predation? Evol. Ecol. 2: 37-50.

Martin, T.E. 1992. Interaction of nest predation and food limitation in reproductive strategies. Curr. Ornithol. 9: 163-197.

Martin, T.E. 1995. Avian life history evolution in relation to nest sites, nest predation, and food. Ecol. Monogr. 65: 101-127.

Smith, P.A. 2003. Factors affecting nest site selection and reproductive success of tundra nesting shorebirds. M.Sc. thesis, University of British Columbia, Vancouver, B.C.

Stenhouse, I.J. 2003. The reproductive behaviour and ecology of Sabine's Gulls (Xema sabini) in the eastern Canadian Arctic. Ph.D. thesis, Memorial University of Newfoundland, St. John's, N.L.

Stenhouse, I.J., Gilchrist, H.G., and Montevecchi, W.A. 2001. Reproductive biology of Sabine's Gull in the Canadian Arctic. Condor, 103(1): 98-107.

Stenhouse, I.J., Gilchrist, H.G., and Montevecchi, W.A. 2004. Reproductive investment and parental roles in Sabine's Gulls (Xema sabini). J. Ethol. 22(1): 85-89.

Stenhouse, I.J., Gilchrist, H.G., and Montevecchi, W.A. 2005. An experimental study examining the anti-predator behaviour of Sabine's Gulls (Xema sabini) during breeding. J. Ethol. 23(2): $103-108$.

Topping, C.J., and Sunderland, K.D. 1992. Limitations to the use of pitfall traps in ecological studies exemplified by a study of spiders in a field of winter wheat. J. Appl. Ecol. 29: 485-491.

Van den Berghe, E. 1992. On pitfall trapping invertebrates. Entomol. News, 103: 149-156.

Vollenweider, R.A. (Editor). 1969. A manual on methods for measuring primary production in aquatic environments: IBP Handbook No. 12. Blackwell, Oxford. 